\title{
Evaluating Acceptability of Cellular Glucose Meter Use in a Diabetes Care Management Program: A Qualitative Study
}

Daniel J Amante ${ }^{1}$, MPH; Timothy P Hogan ${ }^{1,2}$, PhD; Thomas M English ${ }^{1}, \mathrm{PhD}$; Ruby W Fairchild ${ }^{3}$, BA; David M Harlan $^{3}$, MD; Michael J Thompson ${ }^{3}$, MD

\footnotetext{
${ }^{1}$ Division of Health Informatics and Implementation Science, Department of Quantitative Health Sciences, University of Massachusetts Medical School, Worcester, MA, United States

${ }^{2}$ Center for Healthcare Organization and Implementation Research (CHOIR), eHealth Quality Enhancement Research Initiative (QUERI), National eHealth QUERI Coordinating Center, Bedford, MA, United States

${ }^{3}$ Diabetes Center of Excellence, Department of Medicine, University of Massachusetts Medical School, Worcester, MA, United States
}

\section{Corresponding Author:}

Daniel J Amante, MPH

Division of Health Informatics and Implementation Science

Department of Quantitative Health Sciences

University of Massachusetts Medical School

368 Plantation Street

Worcester, MA, 01605

United States

Phone: 15088568480

Fax: 15088568993

Email: daniel.amante@umassmed.edu

\begin{abstract}
Background: Diabetes is difficult to manage and many patients require additional support to control their disease. Increasingly, connected health technologies, such as secure patient portals, are being used in diabetes care management programs to provide such support. Uploading self-monitored blood glucose (SMBG) recordings to patient portals is an increasingly common strategy to support improved monitoring. Recently introduced cellular glucose meters can be used to automate the upload process immediately after testing. Automatic uploading eliminates the need for patients to connect meters to a computer and enables support teams to monitor uploads in real-time and in turn, provide in-the-moment support as needed. Despite their potential to improve diabetes management, the use of cellular glucose meters is not without challenges. Although designed for simplicity and seamless use, meters sometimes require a degree of technological skill that certain patients may not possess. Patients may also struggle to understand how to best utilize functionality to help manage their disease. When perceived ease of use or usefulness is low, utilization of the technology may result in unanticipated consequences. For this reason, patient acceptability must be evaluated before cellular glucose meters can be implemented more broadly.
\end{abstract}

Objective: To evaluate patient acceptability of cellular glucose meter use in a diabetes care management program.

Methods: Patients with Type 1 and Type 2 diabetes received cellular glucose meters and were enrolled in a care management program. Certified Diabetes Educators (CDEs) monitored uploaded SMBG recordings. The CDEs provided structured support and coaching to participants and interacted with their medical providers as necessary. After 1 month of the program, focus groups and semi-structured phone interviews were conducted with the participants. Audio recordings of each were transcribed verbatim and the resulting transcripts were thematically coded. An a priori code list, based on the Technology Acceptance Model, was used to guide the analysis and further codes were added to represent other themes from the transcripts.

Results: Participants with Type $1(n=6)$ or Type $2(n=10)$ diabetes reported that the cellular glucose meter was both easy to use and useful. The meter's most favorable features were the automatic and seamless uploading of SMBG recordings, SMBG tracking and sharing tools, and tips provided through the meter. The support provided by the CDEs through the management program was also identified as being helpful. Identified areas of improvement included providing training on the meter and program, improved consistency and efficiency of the meter's functional performance, and additional meter functionality. 
Conclusions: All participants reported a positive overall experience using the meter as part of the care management program. Future work should focus on long-term patient acceptability and efficacy of using cellular glucose meters in diabetes management programs and the subsequent effects on clinical service utilization and provider workflow.

(iProc 2015;1(1):e2) doi: 10.2196/iproc.4637

\section{KEYWORDS}

medical informatics, health information technology, health communication, health information management, diabetes mellitus, patient care management

(This is a conference paper presented at the Connected Health Symposium, Boston, 2015, which was not edited and is only lightly peer-reviewed).

\section{Multimedia Appendix 1}

Extended Abstract.

\section{[PDF File (Adobe PDF File), 216KB-Multimedia Appendix 1]}

\section{References}

1. Haas L, Maryniuk M, Beck J, Cox CE, Duker P, Edwards L, 2012 Standards Revision Task Force. National standards for diabetes self-management education and support. Diabetes Care 2014 Jan;37 Suppl 1:S144-S153 [FREE Full text] [doi: 10.2337/dc14-S144] [Medline: 24357210]

2. Valdez RS, Holden RJ, Novak LL, Veinot TC. Transforming consumer health informatics through a patient work framework: connecting patients to context. J Am Med Inform Assoc 2015 Jan;22(1):2-10. [doi: 10.1136/amiajnl-2014-002826] [Medline: 25125685]

3. C. and A. Strauss, Managing chronic illness at home: three lines of work. Qualitative sociology 1985;8(3):224-247. [doi: 10.1007/BF00989485]

4. Berg M. Patient care information systems and health care work: a sociotechnical approach. Int J Med Inform 1999 Aug;55(2):87-101. [Medline: 10530825$]$

5. Phillips A. Web based care management improved glucose control in patients with poorly controlled diabetes. Evid Based Nurs 2006 Jan;9(1):21. [Medline: 16437803]

6. Taylor CB, Miller NH, Reilly KR, Greenwald G, Cunning D, Deeter A, et al. Evaluation of a nurse-care management system to improve outcomes in patients with complicated diabetes. Diabetes Care 2003 Apr;26(4):1058-1063. [Medline: $\underline{12663573]}$

7. Aubert RE, Herman WH, Waters J, Moore W, Sutton D, Peterson BL, et al. Nurse case management to improve glycemic control in diabetic patients in a health maintenance organization. A randomized, controlled trial. Ann Intern Med 1998 Oct 15;129(8):605-612. [Medline: 9786807]

8. Piette JD, Weinberger M, Kraemer FB, McPhee SJ. Impact of automated calls with nurse follow-up on diabetes treatment outcomes in a Department of Veterans Affairs Health Care System: a randomized controlled trial. Diabetes Care 2001 Feb;24(2):202-208. [Medline: 11213866]

9. Krein SL, Klamerus ML, Vijan S, Lee JL, Fitzgerald JT, Pawlow A, et al. Case management for patients with poorly controlled diabetes: a randomized trial. Am J Med 2004 Jun 1;116(11):732-739. [doi: 10.1016/j.amjmed.2003.11.028] [Medline: 15144909]

10. Hess R, Bryce CL, Paone S, Fischer G, McTigue KM, Olshansky E, et al. Exploring challenges and potentials of personal health records in diabetes self-management: implementation and initial assessment. Telemed J E Health 2007 Oct;13(5):509-517. [doi: 10.1089/tmj.2006.0089] [Medline: 17999613]

11. Zickmund SL, Hess R, Bryce CL, McTigue K, Olshansky E, Fitzgerald K, et al. Interest in the use of computerized patient portals: role of the provider-patient relationship. J Gen Intern Med 2008 Jan;23 Suppl 1:20-26 [FREE Full text] [doi: 10.1007/s11606-007-0273-6] [Medline: 18095039]

12. Quinn CC, Clough SS, Minor JM, Lender D, Okafor MC, Gruber-Baldini A. WellDoc mobile diabetes management randomized controlled trial: change in clinical and behavioral outcomes and patient and physician satisfaction. Diabetes Technol Ther 2008 Jun;10(3):160-168. [doi: 10.1089/dia.2008.0283] [Medline: 18473689]

13. Grant RW, Wald JS, Schnipper JL, Gandhi TK, Poon EG, Orav EJ, et al. Practice-linked online personal health records for type 2 diabetes mellitus: a randomized controlled trial. Arch Intern Med 2008 Sep 8;168(16):1776-1782 [FREE Full text] [doi: 10.1001/archinte.168.16.1776] [Medline: 18779465]

14. Amante DJ, Hogan TP, Pagoto SL, English TM. A systematic review of electronic portal usage among patients with diabetes. Diabetes Technol Ther 2014 Nov;16(11):784-793. [doi: 10.1089/dia.2014.0078] [Medline: 24999599] 
15. L., J. Ingham, and P. Collerette, Why do people use information technology? A critical review of the technology acceptance model. Information \& management 2003;40(3):191-204. [doi: 10.1016/S0378-7206(01)00143-4]

Edited by G Eysenbach, T Hale; submitted 12.05.15; peer-reviewed by T Irizarry, S Beidas, C Berridge; accepted 20.07.15; published 27.10.15

Please cite as:

Amante DJ, Hogan TP, English TM, Fairchild RW, Harlan DM, Thompson MJ

Evaluating Acceptability of Cellular Glucose Meter Use in a Diabetes Care Management Program: A Qualitative Study

iProc 2015;1(1):e2

URL: $\underline{\text { http://www.iproc.org/2015/1/e2/ }}$

doi: 10.2196/iproc.4637

PMID:

CDaniel J. Amante, Timothy P. Hogan, Thomas M. English, Ruby W. Fairchild, David M. Harlan, Michael J. Thompson. Originally published in JMIR Mhealth and Uhealth (http://www.iproc.org), 27.10.2015. This is an open-access article distributed under the terms of the Creative Commons Attribution License (http://creativecommons.org/licenses/by/2.0/), which permits unrestricted use, distribution, and reproduction in any medium, provided the original work, first published in JMIR mhealth and uhealth, is properly cited. The complete bibliographic information, a link to the original publication on http://mhealth.jmir.org/, as well as this copyright and license information must be included. 